\title{
DEVELOPING PROCEDURES AND GUIDANCE FOR PERFORMING AN ENVIRONMENTAL ASSESSMENT OF US WOODEN PALLETS
}

\author{
SEVDA ALANYA-ROSENBAUM ${ }^{1}$, RICHARD BERGMAN $^{1}$ \& BRAD GETHING ${ }^{2}$ \\ ${ }^{1}$ USDA Forest Service, Forest Products Laboratory, Wisconsin, USA \\ ${ }^{2}$ National Wooden Pallet \& Container Association, Virginia, USA
}

\begin{abstract}
Because of the increasing demand for sustainable products and services at a global level, manufacturers are encouraged to document the environmental performance of their products and services. This helps to enhance efficiency of supply chain and create value for stakeholders. Declaration of environmental performance supports manufacturers' claims for products such as wood products, which many stakeholders consider more environmentally benign than other products. Through the internationally accepted life-cycle assessment (LCA) tool, many wood products have been shown to be less energy intensive and generate less greenhouse gas emissions than their non-wood alternatives. However, until now, solid wooden pallets have not been studied in detail. This is the first study of this type because of the complexities of wooden pallet production, sizing, usage, reparability, and durability. For this project, the LCA analysis will provide a comprehensive understanding of environmental performance especially from the wooden pallet recovery side and thus can be used to identify potential improvements in the sector as well. The project goal is to conduct a cradle-to-grave environmental assessment of wooden pallet production throughout the whole life cycle of pallets using the LCA tool. The study will investigate the current state of wooden pallet manufacturing in the United States using up-to-date sectoral data from at least $20 \%$ of the production of the US wooden pallet industry. The resultant source data will be used to model the life cycle of wooden pallets and perform the life-cycle impact assessment that will underpin a sectoral environmental product declaration (EPD) for wooden pallet manufacturing in the United States. This paper presents the methodology development for standardization of LCA in wooden pallet manufacturing, which will provide the basis for development of the first wooden pallet product category rule (PCR) and the subsequent EPDs for wooden pallets. The objective is to provide guidelines and enhance development of environmental EPDs in US wooden pallet production for the shift toward more sustainable manufacturing.
\end{abstract}

Keywords: life-cycle assessment, wooden pallet, environmental performance, product category rules.

\section{INTRODUCTION}

Declarations of environmental performance are currently of great interest to industry and their customers because of growing awareness of environmental protection and government legislation. Thus, setting sustainability goals and moving toward sustainable manufacturing enhances competitiveness of companies in the market. This brings about the need for documentation of their environmental performance using recognized standards, which will guarantee that the information provided is reliable, is easy to understand, and uses scientifically accepted methods, such as life-cycle assessment (LCA).

LCA is a well-established and widely recognized method for sustainability assessment and environmental performance reporting that has been used for decades. LCA allows quantification of overall environmental impact of a product or service throughout its life cycle, and it is currently used for both documenting environmental performance and as a driver for progress toward sustainable production. The International Organization for Standardization (ISO) developed an approach for conducting LCAs as a part of standardization efforts [1], [2]. The LCA tool is composed of four stages: (1) goal and scope, which details the purpose and scale of the project; (2) life-cycle inventory (LCI), which 
covers data collection and measurement of environmental inputs and outputs; (3) life-cycle impact assessment (LCIA), which aggregates LCI outputs to estimate specific environmental and human health impacts; and (4) interpretation, which interprets what is occurring and what can be done to improve the environmental performance of the studied product.

Although LCA is a well-developed and comprehensive method including detailed data analysis, the results from different LCA studies are not always comparable or objective. Environmental product declarations (EPDs) are developed to address these issues and for declaration of environmental performance based on a standardized, common methodology used for performance evaluation. EPDs are third-party-verified documentation of environmental performance that follow a scientifically accepted and objective methodology detailed by a product category rule (PCR). EPDs are generated in accordance with ISO 14025 type III environmental declaration reference standards that describe the principles and procedures of EPDs based on LCAs performed in line with ISO 14040/14044 standards [1][3]. In the United States, to support development of sustainable supply chains for wood products, EPDs have been developed for many structural wood products in alignment with the North American structural and architectural wood products PCR [4], [5]. Wooden pallets are not considered structural or architectural. Therefore, they do not fit within the North American wood product PCR [4] and thus require their own PCR to be developed for objective comparisons, which will be discussed in more detail later.

Wooden pallets used for shipping are a critical component of the complex global supply chain of many products. And, with growing use of EPDs by companies aiming to improve their competitiveness and enhance their supply chain sustainability, the need for reporting verifiable environmental performance in the wooden pallet industry also increases [6], [7]. Therefore, the goal of this study is to develop a sectoral cradle-to-grave LCI and perform an LCIA to assess the environmental sustainability of wooden pallet manufacturing. Using the LCA developed in this project, the National Wooden Pallet and Container Association (NWPCA) will create a wooden pallet EPD for a general multiple-use-type wooden pallet. The resulting document will provide guidance to the wooden pallet sector for environmental performance assessment and will enhance knowledge for developing EPDs in this industry. This paper presents the methodology used for providing guidance and resources for the wooden pallet industry to perform an LCA and roadmap to develop EPDs. This is the first study of this type to link LCA and EPD development together because of the inherent complexities of wooden pallet production, sizing, usage, reparability, and durability.

\section{BACKGROUND}

Wooden pallets are used for handling, shipping, and storing a variety of goods. Currently, more than 1.8 billion pallets are in service in the United States [8]-[12]. LCA has commonly been used for wooden pallet manufacturing supply chain sustainability assessment [13]-[19]. There have been a number of studies investigating the environmental impact of pallet repair and remanufacturing and the recovery phase of the supply chain [20], [21]. There are some reports presenting comparative analyses of wooden and plastic pallets [22], [23]. But, the increasing interest for verified and standardized environmental data reporting highlights the opportunity for the wooden pallet industry to develop EPDs. Yet, EPDs are developed according to sectoral PCR, which defines the rules and requirements for EPDs specific to a certain product. PCR provides the guidelines or framework for LCAs, enabling the transparency and comparability between different environmental assessments for the same product. PCR development can be aided by previous PCRs [3]. Unfortunately, no current wooden pallet PCR exists globally, although work has been started by the International EPD $^{\circledR}$ System (www.environdec.com). However, this work currently only focuses on non- 
construction (primary) wood production, but it may eventually include pallet parts as secondary products and finally wooden pallets as a tertiary product. Thus, this nonconstruction PCR will not consider the entire supply chain as this project will. Therefore, the other objective of this ongoing study is to develop a PCR for wooden pallets, which will allow standardization of LCA for the wooden pallet sector and can be used in the preparation of EPDs. Consequentially, the results of this sectoral LCA study that will be performed will be used for the preparation of a wooden pallet PCR.

\section{LIFE-CYCLE ANALYSIS METHODOLOGY}

\subsection{Scope of the study}

The scope of this LCA study covers the life-cycle stages of wooden pallet manufacturing starting from forest resource activities through end-of-life. The cradle-to-grave system boundary include manufacturing, transportation, and re-use, recycling, or disposal of pallets (Fig. 1). This study represents the US wooden pallet primary manufacturing and recycling sector, including analyses of wooden pallets with different feedstock material, i.e. softwood and hardwood, and focusing on multi-use pallets, because these products represent the US wooden pallet market [24]. This study does not include single-use or special-use pallets but instead focuses on general-use and reusable pallets. Reusable pallets are intended for more than one unit load. The infrastructure and manufacturing, maintenance, and disposal of production equipment used in the system is not considered within the scope of this study. The product-use phase, which includes transportation of goods using wooden pallets, is subject to great variability and uncertainty. Therefore, the use phase is also left outside of the scope of this study. Transportation of raw materials and new, recovered, and disposed pallets will be accounted for.

In this study, the ISO 14040 and 14044 international standards are being followed for application of LCA [1], [2].

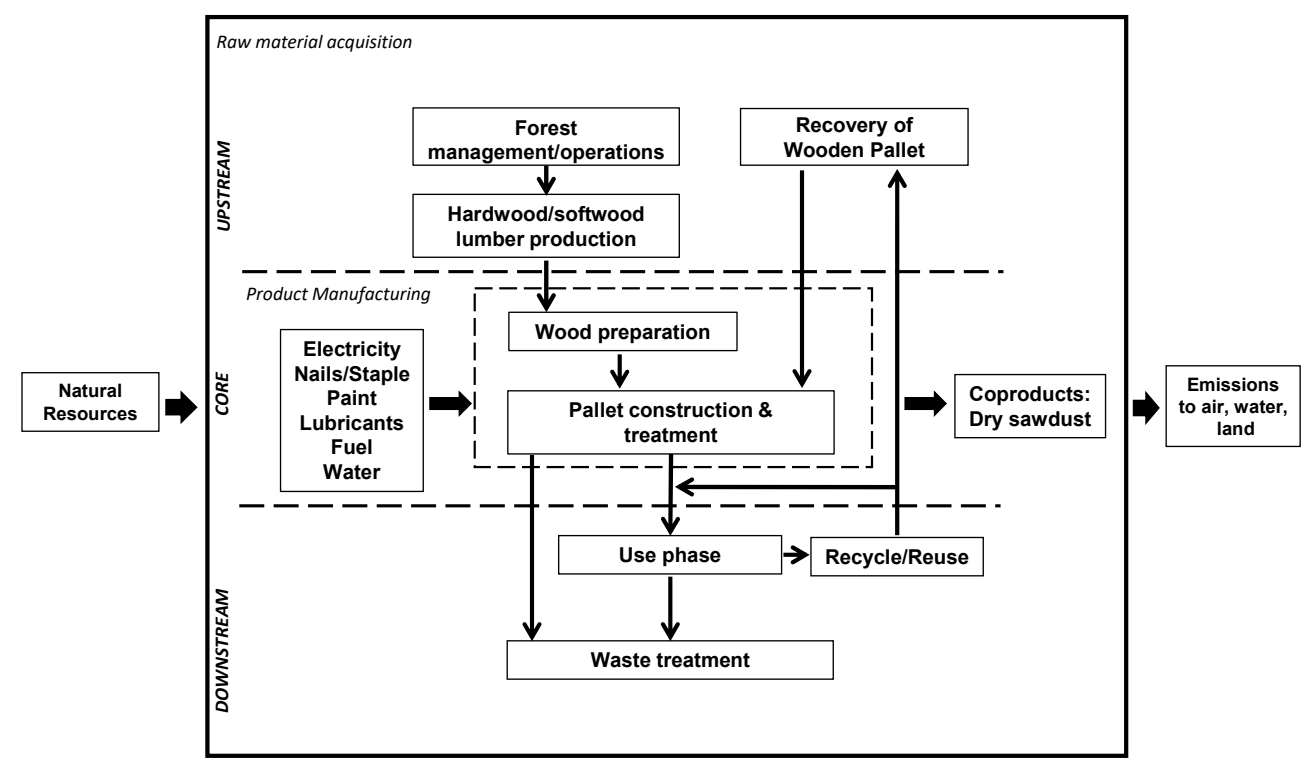

Figure 1: Life cycle of multi-use wooden pallet production in the United States. 


\subsection{Functional unit}

The functional unit is a measure of the function of the service or product generated by the system under investigation. It is used to normalize the material and energy inputs and outputs and environmental impacts of the system based on the function of the product. One of the main challenges in this study regarding the LCA-PCR development was to define a functional unit for the wooden pallet LCA that can be used for normalizing environmental burden of different types of pallets produced. The challenge was mainly caused by the wide range of designs, size, and carrying capacity of wooden pallets produced in the market. Variety in pallet designs and carrying capacity caused difficulty in durability assessment of multi-use pallets, which is the focus of this study. In addition, service life of a pallet is also highly variable depending on wood species, the use phase, and service environment conditions [25]. Handling and loading conditions have a significant impact on pallet durability and trip numbers [25].

The functional unit selected was 1,000 pallet loads of product delivered using wooden pallets. The number of pallets required to make 1,000 trips will be calculated using the estimated trip number that a wooden pallet makes. Trip number is well suited to quantify multi-use pallets as a general metric for the various products of the wooden pallet industry. Yet, only defining the trip number that a pallet makes is not sufficient for normalization of the function because trip number depends on a variety of factors. To achieve a normalized functional unit, the trip number per wooden pallet will be estimated using FasTrack test protocol coupled with another test protocol used for durability assessment to minimize variability in the test results. FasTrack test protocol, developed at the Center for Unit Load Design of Virginia Tech University, will be used to quantify the average number of trips a pallet can make [26]. In this way, trip numbers a pallet can make will be identified by testing the pallet under investigation taking into account the design, handling, and loading conditions using a recognized test. Using this protocol to identify the functional unit for a pallet with a specific design and carrying capacity will allow analysis with unified and comparable measures.

Wood pallets are produced in various designs differing in size and dimensions of pallet components. The most commonly used wooden pallets in the United States' supply chain are Grocery Manufacturers Association (GMA) style pallets with specifications of 48 by 40 inches $(1.2$ by $1.0 \mathrm{~m})$ and 2,800 pounds $(1,270 \mathrm{~kg})$ of maximum load-carrying capacity for a variety of support and handling conditions [11], [27]. These pallet specifications will be used as the basis for industry-wide LCA analysis. There are two main categories of wooden pallet designs used in the United States: stringer-class and block-class assembly. The major functional difference between stringer pallets (Fig. 2) and block pallets (Fig. 3) is the number of openings accepting handling equipment. Block pallets are designed to have access for full four-way entry by forklifts and pallet jacks, whereas stringer pallets are designed for access on two sides. Stringer pallets can be converted to a partial four-way entry for fork lifts by notching the stringers. To take into account the different pallet designs and different feedstock material, three different pallet designs will be considered, representing the most typical designs manufactured by the wooden pallet industry in the United States. Three pallet types will be considered: hardwood stringer GMA, softwood stringer GMA, and softwood block GMA. In this study, FasTrack test protocol will be used to quantify average number of trips using 30 replicate tests for each pallet type investigated. 


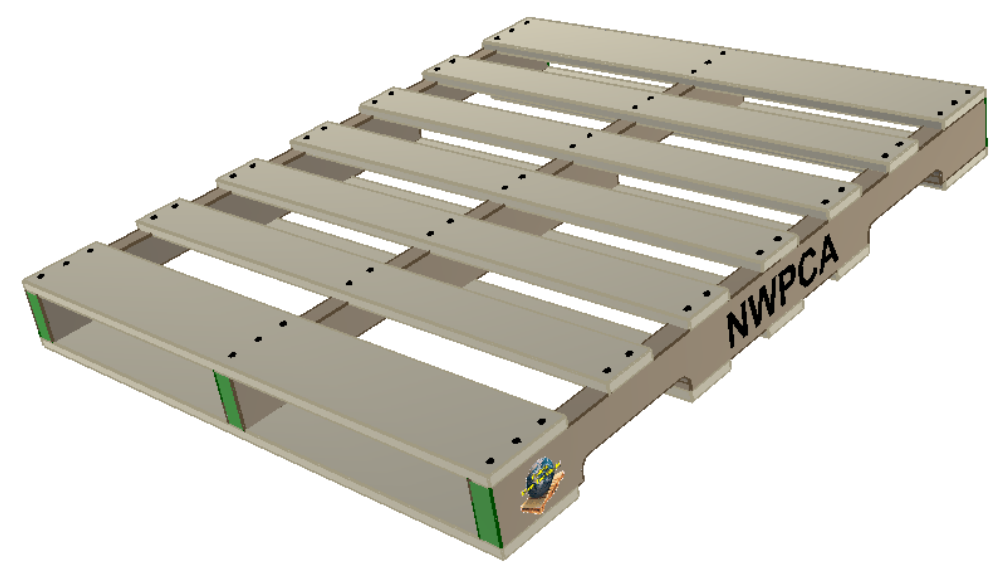

Figure 2: Schematic diagram of a stringer pallet.

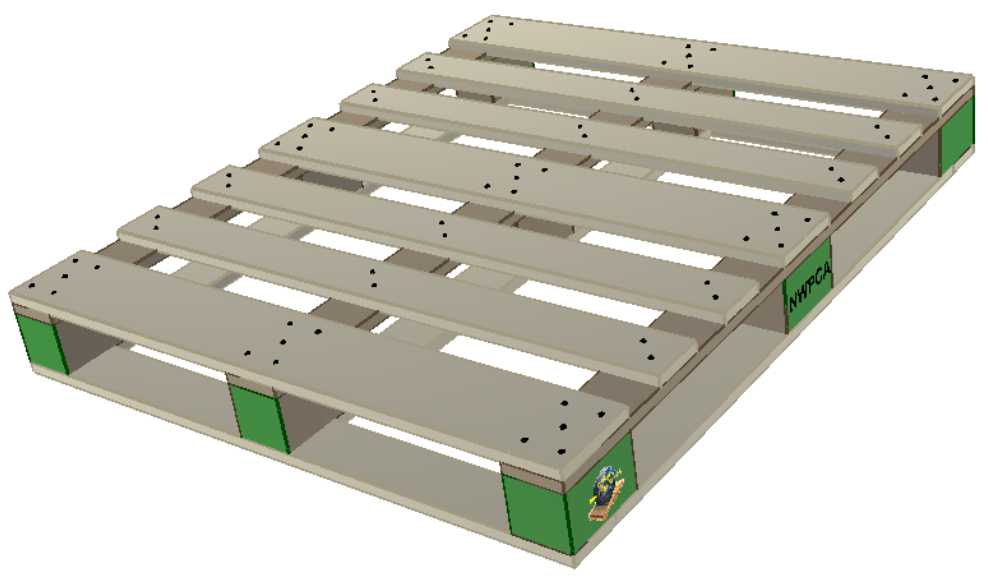

Figure 3: Schematic diagram of a block pallet.

\subsection{System boundary}

This project will consider the cradle-to-grave system boundary analysing the whole life cycle of a wooden pallet from resource extraction (cradle) to disposal phase (grave). The wood flow of a multi-use wooden pallet is presented in Fig. 1. The system boundary showing the wood flow is established to represent the current production in the United States to cover different manufacturing processes. The system boundary begins with forest regeneration and ends at the end-of-life stage of a wooden pallet. The forest management and operations include site preparation and planting seedlings, forest management including fertilization and thinning, harvesting, transportation of saw logs to the lumber manufacturing facility, and lumber production. The lumber production stage includes production of rough sawn lumber. Wooden pallets are typically made of industrial-grade lumber. The pallet manufacturing phase covers common processes of pallet production, i.e. cutting of lumber to appropriate 
size and notching and assembly at the pallet manufacturing facility. Cutting of lumber to size may be performed at the lumber manufacturing facility, yet it is considered in the pallet manufacturing system boundary. Depending on the desired use of the product, some additional processes may be included in the system boundary such as heat treatment or stamping. Heat treatment may be used to comply with International Standards for Phytosanitary Measures No. 15 (ISPM 15) [28], if pallets are used for international consumption, or it may be done because of customer request.

\subsection{Data collection and quality}

The study will investigate the current state of wooden pallet manufacturing in the United States using up-to-date sectoral data from at least $20 \%$ of the production of the US wooden pallet industry. Industry-wide LCI will be generated based on the primary data. Primary data collected through survey questionnaires sent to wooden pallet manufacturing plants and recycling facilities in the United States will be based on annual production for year 2016/2017. Primary data are those measured and collected in-person and on-site. Secondary data for processes not specifically pertaining to wooden pallet operations described in Fig. 1, such as fuel and electricity production, will be derived from peer-reviewed literature and LCI databases including the DATASMART LCI package [29], [30] found with the LCA modelling software. Data collection is the most time-consuming part of an LCA, and its quality is paramount to generating the best outputs. Mass and energy balances for each facility along with overall sector balances will be conducted to ensure appropriate data quality.

\subsection{Life-cycle impact assessment}

LCIA aggregates the LCI flows into critical environmental impact categories. The impact categories to be examined in this study include global warming (GW) ( $\mathrm{kg} \mathrm{CO} \mathrm{CO}_{2}$-eq), acidification ( $\mathrm{kg} \mathrm{SO}$-eq), eutrophication ( $\mathrm{kg} \mathrm{N}$-eq), ozone depletion (OP) (kg chlorofluorocarbons-11-eq), smog formation ( $\mathrm{kg} \mathrm{O}_{3}$-eq), human health (CTU), and eco toxicity (CTU). Among the available methods for the LCIA, the Tool for the Reduction and Assessment of Chemical and Other Environmental Impacts (TRACI) will be used in this study [31]. TRACI is a midpoint level impact assessment model developed by the US Environmental Protection Agency and is specifically representative for the United States using input parameters consistent with US conditions.

\subsection{Next steps}

The initiative between the USDA Forest Service, Forest Products Laboratory (FPL) and NWPCA as part of a memorandum of understanding is to develop an LCA for the wooden pallet sector. In addition, FPL will support NWPCA in developing sectoral EPDs to fill the information gap in objective and comparable environmental assessments of wooden pallets. Future work includes taking steps toward the creation of the PCR committee and development of wooden pallet PCR that is applicable to the different types of wooden pallets manufactured. This work will be performed in parallel with the sectoral wooden pallet LCA study that will form the basis for the PCR document.

\section{ACKNOWLEDGEMENTS}

The project is funded in part by the National Wooden Pallet and Container Association and The Pallet Foundation through a cooperative agreement with the United States Department 
of Agriculture, Forest Service, Forest Products Laboratory, No. 16-CO-11111137-092. This research was supported in part by an appointment to the USDA Forest Service Research Participation Program administered by the Oak Ridge Institute for Science and Education (ORISE) through an interagency agreement between the US Department of Energy and the US Department of Agriculture, Forest Service. ORISE is managed by Oak Ridge Associated Universities (ORAU) under DOE contract number DE-AC05-06OR23100. All opinions expressed in this paper are those of the authors and do not necessarily reflect the policies and views of USDA, DOE, or ORAU/ORISE. The authors acknowledge the following peer reviewers: Andres L. Carrano, Professor and Associate Dean for Research, Georgia Southern University; Shaobo Liang, Post-doctoral fellow, USDA Forest Service, Forest Products Laboratory; Kamalakanta Sahoo, Post-doctoral fellow, USDA Forest Service, Forest Products Laboratory.

\section{REFERENCES}

[1] ISO, ISO 14040: Environmental management—-life-cycle assessment — principles and framework, International Organization for Standardization: Geneva, Switzerland, 2006.

[2] ISO, ISO 14044: Environmental management-life-cycle assessment-requirements and guidelines, International Organization for Standardization: Geneva, Switzerland, 2006.

[3] ISO, ISO 14025: Environmental labels and declarations-Type III environmental declarations-Principles and procedures, International Organization for Standardization: Geneva, Switzerland, 2006.

[4] FPInnovations, Product category rule (PCR): For preparing an environmental product declaration (EPD) for North American structural and architectural wood products. UN CPC 31, NAICS 321, 2015.

[5] American Wood Council/Canadian Wood Council, North American EPD, Online. www.awc.org/sustainability/epd/. Accessed on: 24 Jan. 2018.

[6] Bergman, R. \& Taylor, A., Environmental product declarations of wood products: An application of life cycle information about forest products. Forest Products Journal, 61(3), pp. 192-201, 2011. DOI: doi.org/10.13073/0015-7473-61.3.192.

[7] Ritter, M., Skog, K. \& Bergman, R., Science supporting the economic and environmental benefits of using wood and wood products in green building construction. General Technical Report FPL-GTR-206, US Department of Agriculture, Forest Service, Forest Products Laboratory: Madison, WI, p. 9, 2011. DOI: doi.org/10.2737/FPL-GTR-206.

[8] Buehlmann, U., Bumgardner, M. \& Fluharty, T., Ban on landfilling of wooden pallets in North Carolina: An assessment of recycling and industry capacity. Journal of Cleaner Production, 17(2), 2009. DOI: doi.org/10.1016/j.jclepro.2008.06.002.

[9] Araman, P., Bush, R. \& Hager, E., U.S. wood pallet material use trends. Processing technologies for the forest and biobased products industries. Proceedings of the 1st International Conference, pp. 208-210, 2010.

[10] Trebilcock, B., Talking pallets with modern readers. Modern Materials Handling, Online. www.litco.com/wp-content/uploads/2013-MMH-Pallet-Report.pdf. Accessed on: Sep. 2013.

[11] National Wooden Pallet and Container Association (NWPCA), Environmental benefits of wood-use for pallets, Online. www.palletcentral.com/?page= DidYouKnow. Accessed on: 6 Apr. 2016. 
[12] PR Newswire, US Pallet Market, Online. www.prnewswire.com/news-releases/uspallet-market-300138714.html. Accessed on: 6 Apr. 2016.

[13] Ng, R., Shi, C., Tan, H. \& Song, B., Avoided impact quantification from recycling of wood waste in Singapore: An assessment of pallet made from technical wood versus virgin softwood. Journal of Cleaner Production, 65, pp. 447-457, 2014. DOI: doi.org/10.1016/j.jclepro.2013.07.053.

[14] Carrano, A., Pazour, J., Debjit, A. \& Thorn, B., Selection of pallet management strategies based on carbon emissions impact. International Journal of Production Economics, 164, pp. 258-270, 2015. DOI: doi.org/10.1016/j.ijpe.2014.09.037.

[15] Carrano, A., Thorn, B. \& Woltag, H., Characterizing the carbon footprint of wood pallet logistics. Forest Products Journal, 64(7), pp. 232-241, 2014. DOI: doi.org/10.13073/FPJ-D-14-00011.

[16] Bengtsson, J. \& Logie, J., Life cycle assessment of one-way and pooled pallet alternatives. The 22nd CIRP Conference on Life Cycle Engineering, pp. 414-419, 2015.

[17] García-Duranona, L., Farreny, R., Navarro, P. \& Boschmonart-Rives, J., Life cycle assessment of a coniferous wood supply chain for pallet production in Catalonia, Spain. Journal of Cleaner Production, 137, pp. 178-188, 2016. DOI: doi.org/10.1016/j.jclepro.2016.07.032.

[18] Gasol, C., Farreny, R., Gabarrell, X. \& Rie, J., Life cycle assessment comparison among different reuse intensities for industrial wooden containers. The International Journal Life Cycle Assessment, 13(5), pp. 421-431, 2008. DOI: doi.org/10.1007/ s11367-008-0005-0.

[19] Franklin Associates, Life Cycle Inventory of Wood Pallet Systems: Final Summary Report for Chep America, Prairie Village, KS, USA, 2007.

[20] Tornese, F., Carrano, A., Thorn, B., Pazour, J. \& Roy, D., Carbon footprint analysis of pallet remanufacturing. Journal of Cleaner Production, pp. 1-13, 2016. DOI: doi.org/10.1016/j.jclepro.2016.03.009.

[21] Park, J., Horvath, L. \& Bush, R., Life cycle inventory analysis of the wood pallet repair process in the United States. Journal of Industrial Ecology, 2017. DOI: doi:10.1111/jiec. 12652 .

[22] ERM (Environmental Resources Management), Streamlined life cycle assessment of iGPS, typical pooled wooden pallets, and single-use wooden pallets-Intelligent Pooling Systems (iGPS) Company LLC, confidential report, Kansas City, USA, 2008.

[23] Edge Environment, Pallet Life Cycle Assessment and Benchmark, Manly, Australia, 2017.

[24] Hardwood Market Report (HMR), Pallet Industry Growth Could Benefit Hardwood Suppliers, PalletCentral, May-June, 2017.

[25] White, M.S. \& Wallin, W.B., Effect of wood pallet design on structural durability: A statistical analysis of observed in-service damage. Forest Products Journal, 37(11), pp. 32-38, 1987.

[26] FasTrack, FastTrack Protocol: VT Unit-load Material Handling FasTrack, Virginia Polytechnic Institute, Center for Unit Load Design: Blacksburg, Virginia, 2008.

[27] Brindley, E., Pallet Standards And Specifications - The Evolution to Today. Pallet Enterprise, Industrial Reporting, Inc.: Ashland, VA, Online. www.palletenterprise.com/articledatabase/view.asp?articleID $=2109$. Accessed on: 8 Jan. 2018. 
[28] FAO (Food and Agriculture Organization of the United Nations), International standard for phytosanitary measures: Regulation of wood packaging material in international trade, Rome, 2009.

[29] NREL, Life Cycle Inventory Database, National Renewable Energy Laboratory, Online. www.lcacommons.gov/nrel/search. Accessed on: 15 Jan. 2018.

[30] Long Trail Sustainability (LTS), DATASMART Life Cycle Inventory, Online. https://tsexperts.com/wp-content/uploads/2017/07/LTS-DATASMART-LCIPackage-Manual_July-2017.pdf. Accessed on: 15 Jan. 2018.

[31] Bare, J., TRACI 2.0: The tool for the reduction and assessment of chemical and other environmental impacts 2.0. Clean Technologies and Environmental Policy, 13(5), pp. 687-696, 2011. DOI: doi.org/10.1007/s10098-010-0338-9. 